\title{
A Filtering Method for Suppressing the Lift-Off Interference in Magnetic Flux Leakage Detection of Rail Head Surface Defect
}

\author{
Yinliang Jia ${ }^{1}$, Yichen Lu ${ }^{1} * * \mathbb{D}$, Longhui Xiong ${ }^{2}$, Yuhua Zhang ${ }^{2}$, Ping Wang ${ }^{1}$ and Huangjian Zhou ${ }^{1}$ \\ 1 College of Automation Engineering, Nanjing University of Aeronautics and Astronautics, \\ Nanjing 210016, China; jyl@nuaa.edu.cn (Y.J.); zeitping@nuaa.edu.cn (P.W.); Samuel@nuaa.edu.cn (H.Z.) \\ 2 Infrastructure Inspection Research Institute, China Academy of Railway Sciences Corporation Limited, \\ Beijing 100081, China; xionglonghui@rails.cn (L.X.); zhangyuhua@rails.cn (Y.Z.) \\ * Correspondence: yichenlu@nuaa.edu.cn
}

check for

updates

Citation: Jia, Y.; Lu, Y.; Xiong, L.; Zhang, Y.; Wang, P.; Zhou, H. A Filtering Method for Suppressing the Lift-Off Interference in Magnetic Flux Leakage Detection of Rail Head Surface Defect. Appl. Sci. 2022, 12, 1740. https://doi.org/10.3390/ app12031740

Academic Editor: Phong B. Dao

Received: 17 January 2022

Accepted: 3 February 2022

Published: 8 February 2022

Publisher's Note: MDPI stays neutral with regard to jurisdictional claims in published maps and institutional affiliations.

Copyright: (C) 2022 by the authors. Licensee MDPI, Basel, Switzerland. This article is an open access article distributed under the terms and conditions of the Creative Commons Attribution (CC BY) license (https:// creativecommons.org/licenses/by/ $4.0 /)$.

\begin{abstract}
Magnetic flux leakage (MFL) detection is a common nondestructive detection method which is usually used to detect the surface defects of steel pipes and rails. To suppress the interference of lift-off on the detection signal of the defects in rail head surfaces, a filtering method is proposed according to the distribution characteristics of the defect leakage magnetic field (LMF) in different directions. The sensor array is used to confirm the reference signal according to the difference between the signals in $\mathrm{x}$ and $\mathrm{z}$ directions. The installation mode of the sensors is deduced according to the distribution of the defect LMF. The experimental results show that this method can effectively suppress the lift-off interference in the MFL signal of the defects in the rail head surfaces.
\end{abstract}

Keywords: rail defects; MFL detection; filtering method; array sensor

\section{Introduction}

Railway is an important mode of public transportation in contemporary society. With the increase in railway running mileage and speed, the risk of the rail defects affected by repeated extrusion, friction, and impact of train wheel sets becomes higher [1].

To keep safe, some nondestructive testing techniques, such as ultrasonic, eddy current, and MFL, have been used in the detection of rail defects [2]. Ultrasonic detection is a widely used and mature rail detection technology $[3,4]$. It is a convenient method for detection of the internal defects of a rail, but due to the need for a coupling agent, ultrasonic detection cannot complete noncontact detection, so the detection speed cannot be further improved, and it is difficult to detect the surface defects by ultrasound.

The eddy current detection needs no exchange agent. It is cheap, simple, and reliable; however, traditional eddy current testing has obvious skin effect, which makes it difficult to detect subsurface defects and is susceptible to the specimen surface state [5].

MFL is an electromagnetic detection technique developed from magnetic particle detection [6]. The advantages of MFL are high sensitivity, high speed, and simple operation. It can detect the surface or subsurface defects [7], but the detection signal is easily affected by the lift-off change, the magnetic field excitation, and others.

The principle of MFL detection is shown in Figure 1. When magnetized ferromagnetic material has defects in its surface, such as cracks, laminations, or magnetic nonuniformities in the manufacturing process, the refraction of the magnetic induction line changes the magnetic circuit, which leads to the leakage of part of the magnetic flux. By detecting the magnetic field above the rail surface with sensors, a defect in the surface can be found and further information about it can be obtained. Multiple sensors are usually arranged along the width of a rail to detect the defect in the entire surface.

The vertical distance from the sensor or yoke to the rail is called lift-off. The LMF of a defect near the rail surface changes quickly in the vertical direction. During detection, the lift-off changes affected by vibration and other factors, thus interfering with the detection 
of the defects. With the development of MFL detection [8-10], various requirements are proposed for railway detection equipment, such as high speed, high efficiency, and high resolution, so interferences such as lift-off interference must be suppressed.

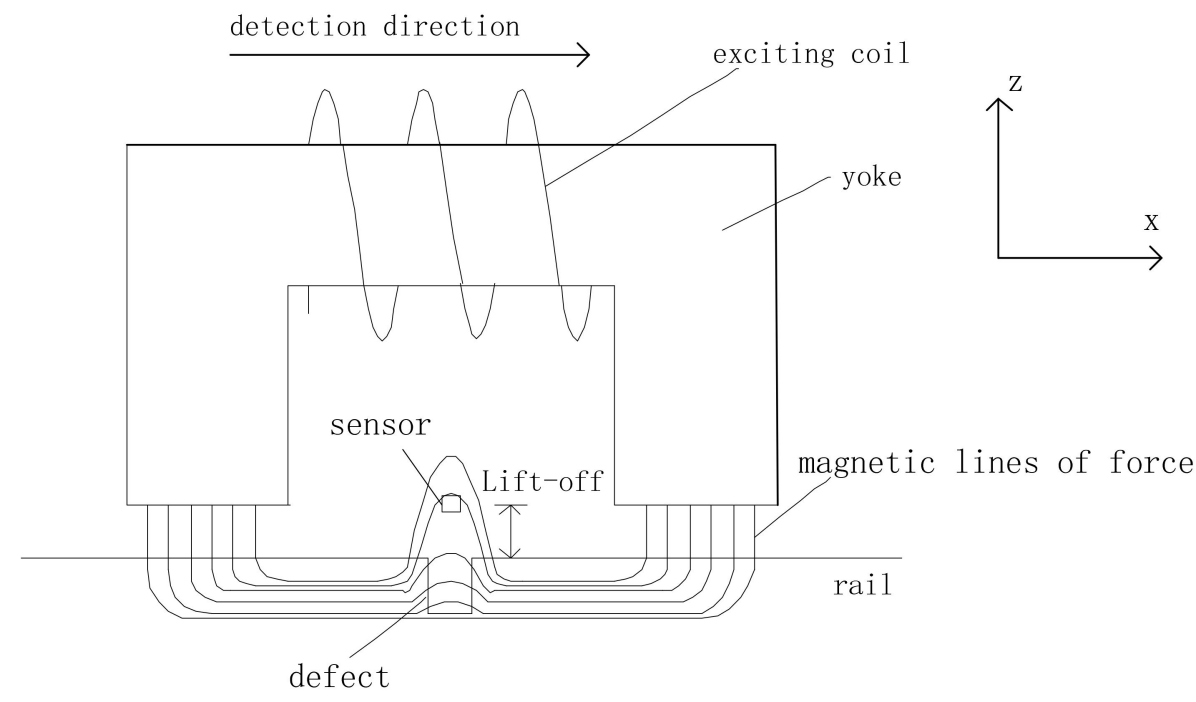

Figure 1. MFL detection.

The interference can be suppressed by hardware such as differential circuit [11], but as the interference is affected by detection speed, the state of the rail surface, and other factors, a circuit is difficult to apply to various situations. Therefore, in addition to hardware filtering, digital filtering is needed. The rail head upper surface defect is a common early defect, and it is usually defected by MFL. This paper presents a method to suppress the lift-off interference in MFL detection.

\section{Related Works}

Researchers have worked a lot on MFL detection for defects, such as the influence of speed on MFL signal [12], magnetization time of high-speed MFL detection [13], and excitation and vibration interference on the signal. In view of the interference, several methods are proposed to suppress the interference.

Karuppasamy optimized the MFL technique by finite element model to detect outer surface defects in ferromagnetic steam generator tubes. In this method, the iron core, coil, coil current, and position of the sensor are optimized, and the MFL signal is predicted. The influence of length, width, and depth of defects on the MFL signal is analyzed. The reliability of detection is improved [14].

A probe consisting of a quantum well Hall-effect sensor, an illuminating electromagnet and sensor circuitry, is designed. This probe is used to apply magnetic fields of various frequencies and field strengths to ascertain a frequency and field range best suited to detecting longitudinal surface-breaking toe cracks in ground mild steel welds [15].

As for the denoising process of the MFL signals, a multilevel filtering approach based on wavelet denoising combined with median filtering is proposed. By analyzing and comparing the denoising properties of three wavelet families, two wavelet bases with the best denoising performance are recognized and selected. Then, the median filtering method is cascaded [16].

To cover the entire workpiece or obtain sufficient data, sensor arrays are used [17]. The researchers carefully set up the position of the sensors in the probe and the relative position of the sensors $[18,19]$. Because the distance between the sensors is close and their vibration is similar, the lift-off interference can be suppressed through the relationship between the signals. 
Ding Shunyi proposes a noise reconstruction algorithm of transverse sensor array and constructed an adaptive interference canceller to filter the multichannel MFL signal of rail treads [20].

Ji Kailun proposed a way of building a virtual channel signal which does not contain any defect. Multiple sensors are arranged, the sensor with the minimum absolute value of signal is considered as having not detected any defect, and this signal is used as a reference signal for filtering [21]. This method suppresses interference to a certain extent, but the lift-off interference and the leakage magnetic field of a defect may be in the reversed phase. It is unreasonable to take the minimum as the reference signal, which will cause certain misjudgment.

A defect detection method of longitudinal array sensors is proposed according to the characteristics of the signals detected by the magnetic sensor in $\mathrm{x}$ and $\mathrm{z}$ directions [22]. The method reduces the misjudgment caused by lift-off interference but is only suitable for judging whether there is a defect and cannot be used for filtering.

The sensor signal changes caused by vibration are found to suppress the lift-off interference, but their methods to find the signal changes are unreasonable [22]. Inspired by these references, this paper presents a method to determine the signal change caused by vibration through the difference between the signals in $\mathrm{x}$ and $\mathrm{z}$ directions of two sensors, to suppress the lift-off noise.

\section{Filtering Method}

\subsection{MFL Analysis}

The detection range of a single magnetic sensor is small because the LMF of a defect is always weak and small. Two rows of magnetic sensors are arranged along the y direction to cover the entire surface of the rail head, as shown in Figure 2. The defects and varied lift-off both change the output of the sensors.

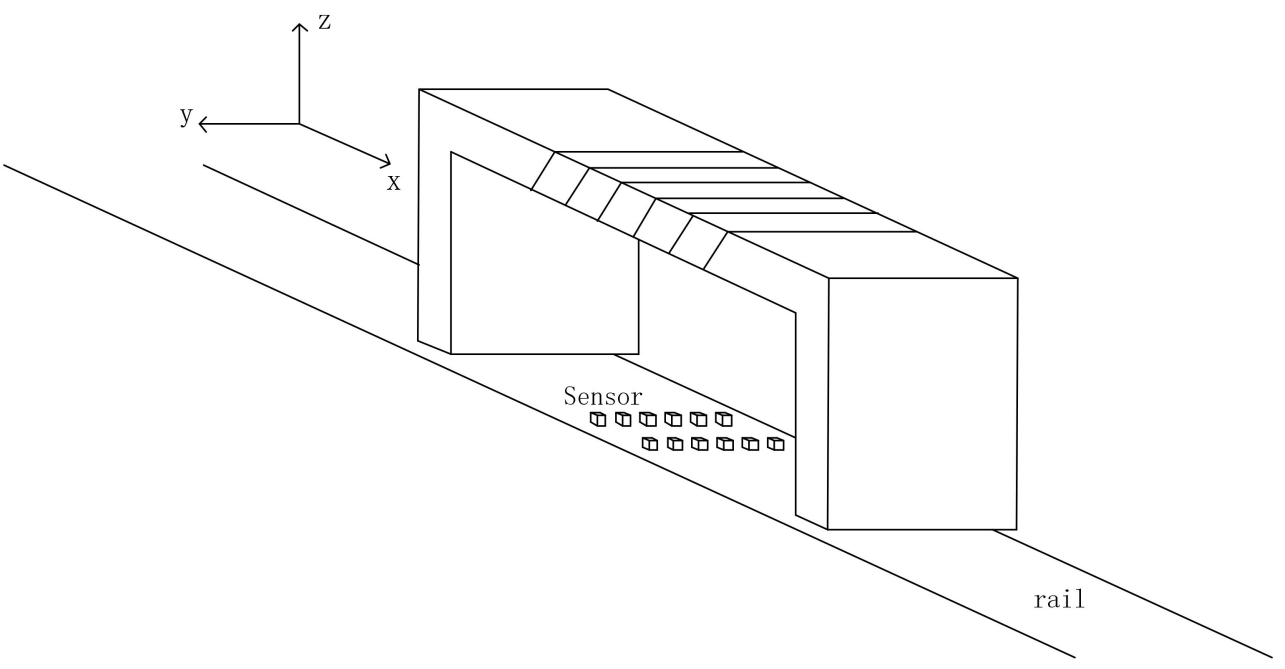

Figure 2. Array sensors layout.

The surface defects are generally distributed near the edge or the center of the rail head, and usually not across the entire surface or perpendicular to the $\mathrm{x}$ direction. Therefore, when the sensors in a row pass through a defect, some magnetic sensors may detect the defect and their outputs change while other sensors do not detect the defect and their outputs do not change by the defect. The output of a sensor that detects the defect is affected by both the defect and the change of the lift-off, while the output of a sensor that does not detect the defect is affected only by the change of the lift-off.

Figure 3 shows the $x$ and $z$ plane near a defect. The defect width and depth are denoted as $2 a$ and $b$, respectively. The distance between the front and rear sensors rows is denoted as 1 , and the lift-off is denoted as $d$. The magnetic field intensity of the point $P(x, z)$ 
above the defect is $\mathrm{H}(\mathrm{x}, \mathrm{z})$ and its $\mathrm{x}$ and $\mathrm{y}$ component are $\mathrm{H}_{\mathrm{x}}(\mathrm{x}, \mathrm{z})$ and $\mathrm{H}_{\mathrm{z}}(\mathrm{x}, \mathrm{z})$, respectively. $\mathrm{H}_{x}(\mathrm{x}, \mathrm{z})$ and $\mathrm{H}_{\mathrm{z}}(\mathrm{x}, \mathrm{z})$ can be obtained by Equations (1) and (2), respectively [19].

$$
\begin{gathered}
\mathrm{H}_{\mathrm{x}}=\mathrm{H}_{\mathrm{x}}(\mathrm{x}, \mathrm{z})=\frac{\sigma_{\mathrm{ms}}}{2 \pi}\left[\tan ^{-1} \frac{\mathrm{b}+\mathrm{z}}{\mathrm{a}-\mathrm{x}}+\tan ^{-1} \frac{\mathrm{b}+\mathrm{z}}{\mathrm{a}+\mathrm{x}}-\tan ^{-1} \frac{\mathrm{z}}{\mathrm{a}-\mathrm{x}}-\tan ^{-1} \frac{\mathrm{z}}{\mathrm{a}+\mathrm{x}}\right] \\
\mathrm{H}_{\mathrm{z}}(\mathrm{x}, \mathrm{z})=\frac{\sigma_{\mathrm{ms}}}{4 \pi} \ln \frac{\left[(\mathrm{x}+\mathrm{a})^{2}+(\mathrm{z}+\mathrm{b})^{2}\right]\left[(\mathrm{x}-\mathrm{a})^{2}+\mathrm{z}^{2}\right]}{\left[(\mathrm{x}-\mathrm{a})^{2}+(\mathrm{z}+\mathrm{b})^{2}\right]\left[(\mathrm{x}+\mathrm{a})^{2}+\mathrm{z}^{2}\right]}
\end{gathered}
$$

where $\sigma_{\mathrm{ms}}$ is the magnetic charge density of the defect side, which can be calculated by Equation (3):

$$
\sigma_{\mathrm{ms}}=5.3\left(\frac{\mathrm{b} / \mathrm{a}+1}{\mathrm{~b} /(\mathrm{a} \mu)+1}\right) \mathrm{H}
$$

where $\mu$ is the magnetic permeability of the material, and $\mathrm{H}$ is the applied magnetic field strength.

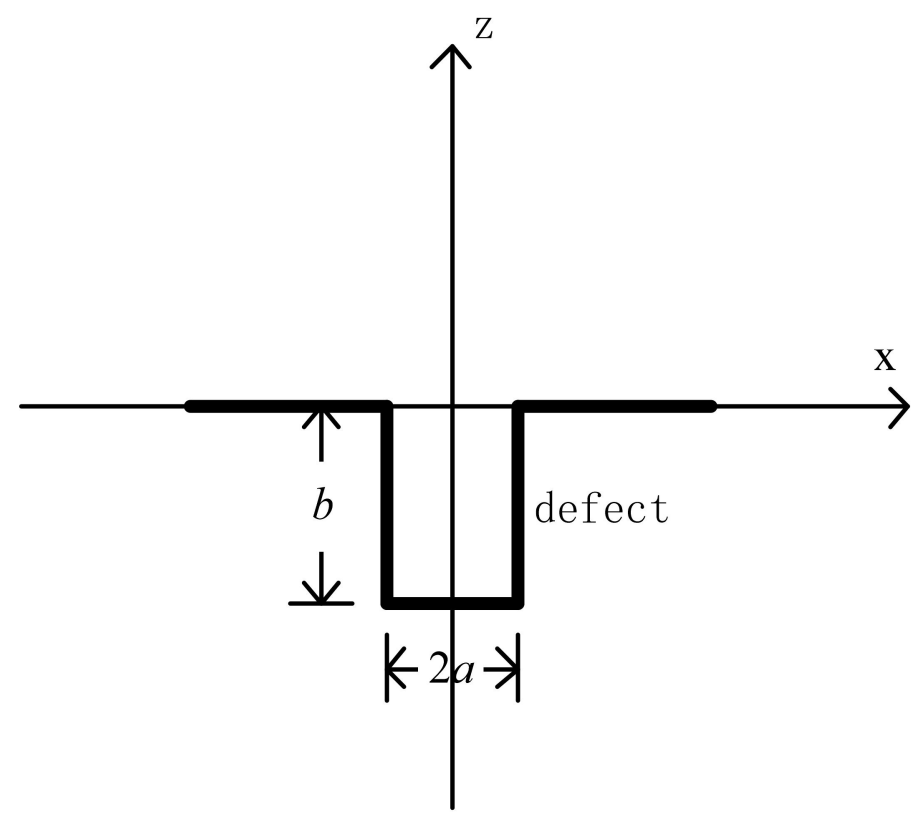

Figure 3. The $x$ and $z$ plane near a defect.

According to Equations (1) and (2), if $\mathrm{z}=1 \mathrm{~mm}, \mathrm{a}=1 \mathrm{~mm}, \mathrm{~b}=1 \mathrm{~mm}$, and $\sigma_{\mathrm{ms}}=1$, the magnetic field distribution in $x$ and $z$ directions of the defect is shown in Figure 4 .

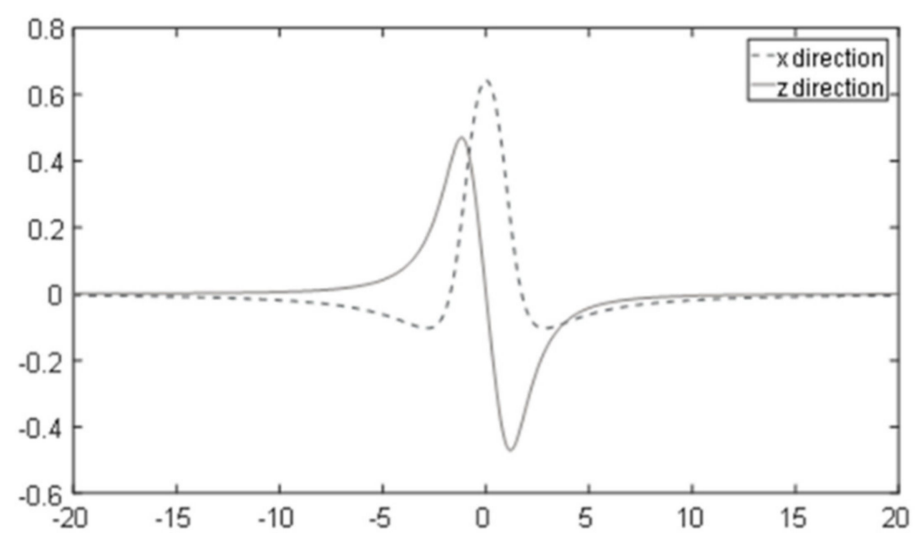

Figure 4. Magnetic field distribution in the $\mathrm{x}$ and $\mathrm{z}$ directions. 


\subsection{Principle of Filtering Method}

According to Figure 4, the maximum of an MFL in the $x$ direction of a defect is directly above the defect, while the maximum and minimum of the MFL in the $\mathrm{z}$ direction is on both sides of it. Two sensors are installed in the front and rear: a sensor which is used to detect the LMF in the $z$ direction is in the front, and the other sensor, which is used to detect the LMF in the $x$ direction, is installed in the rear. When the rear sensor is directly above a defect, its output is the maximum. At this time, the output of the front sensor is negative. The absolute value of the difference between the outputs is larger than that of each output.

Without any defect, the lift-off interference in $\mathrm{x}$ and $\mathrm{z}$ directions are in the same direction. The smaller the lift-off, the greater the output in both $\mathrm{x}$ and $\mathrm{z}$ directions. In a no-defect area, if one sensor measures the LMF in the $x$ direction and the other sensor measures the LMF in the $\mathrm{z}$ direction, the absolute value of the difference between their output signals is smaller than that of each output.

Two sensors which detect the $\mathrm{x}$ and $\mathrm{z}$ directions MFL, respectively, are a pair, and several pairs of sensors are arranged in y the direction, as shown in Figure 2. If the distance between a pair of sensors is reasonable, the smaller the absolute value, the more likely it is that no defect is measured. As described in Section 3.1, there are always several sensors in a row that do not detect the LMF of a defect. It can be considered that the pair of sensors with the smallest absolute value of the difference of their outputs does not detect the LMF of a defect, and their outputs are taken as a reference signal that does not contain the defect signal but only the lift-off interference.

The absolute value of the difference between the outputs of the two sensors should be as large as possible to find the reference signal accurately. If a sensor detects the maximum in the $\mathrm{x}$ direction and the other sensor detects the minimum in the $\mathrm{z}$ direction, the absolute value of the difference between the outputs of the two sensors is the maximum.

According to Equation (1), if the lift-off is $\mathrm{z}_{0}$, which remains unchanged, $\mathrm{H}_{\mathrm{x}}\left(\mathrm{x}, \mathrm{z}_{0}\right)$ is the maximum when $x=0$. According to Figure 4, the minimum of $H_{z}\left(x, z_{0}\right)$ occurs on the positive half-axis of $x$. Due to the small defect, the magnetic dipole model can be introduced to simplify Equation (2) [19].

$$
\mathrm{H}_{\mathrm{z}}(\mathrm{x}, \mathrm{z})=\frac{\sigma_{\mathrm{ms}}}{4 \pi} \ln \frac{\left[(\mathrm{x}-\mathrm{a})^{2}+\mathrm{z}^{2}\right]}{\left[(\mathrm{x}+\mathrm{a})^{2}+\mathrm{z}^{2}\right]}
$$

As the sensors are close to each other and their lift-offs are similar, $\mathrm{z}=\mathrm{z}_{0}$. The derivative of Equation (4) is taken to $\mathrm{x}$ and set as equal to 0 .

$$
\mathrm{H}_{\mathrm{z}}^{\prime}\left(\mathrm{x}, \mathrm{z}_{0}\right)=0
$$

Equation (5) is then solved, that is, $H_{z}\left(x, z_{0}\right)$ is the maximum when $x=-\sqrt{a^{2}+z_{0}^{2}}$, and $H_{z}\left(x, z_{0}\right)$ is the minimum when $x=\sqrt{a^{2}+z_{0}^{2}}$. Obviously, if the distance between two sensors is $\sqrt{a^{2}+z_{0}^{2}}$, when the rear sensor detects the maximum in the $x$ direction, the front sensor detects the minimum in the $\mathrm{z}$ direction.

In actual detection, the spacing, which is denoted as 1 between two sensors, is determined as the minimum width and depth of the defect that should be detected. Figure 5 shows the distribution of LMFs of the defects with different sizes. The distance of 10 is calculated according to the minimum defect. For a large defect, its LMF maximum in the $x$ direction is larger than that of a small defect. When a sensor is direct above a larger defect and its output is the maximum in the $x$ direction, the other sensor with a distance of 10 from this sensor does not measure the minimum in the $\mathrm{z}$ direction. Nevertheless, its output is smaller than the minimum of the minimal defect. In other words, the absolute value of the difference between the outputs of a pair of sensors is greater than that of a small defect. 
Therefore, the spacing of the two sensors set to a small defect is also suitable for detecting large defects.
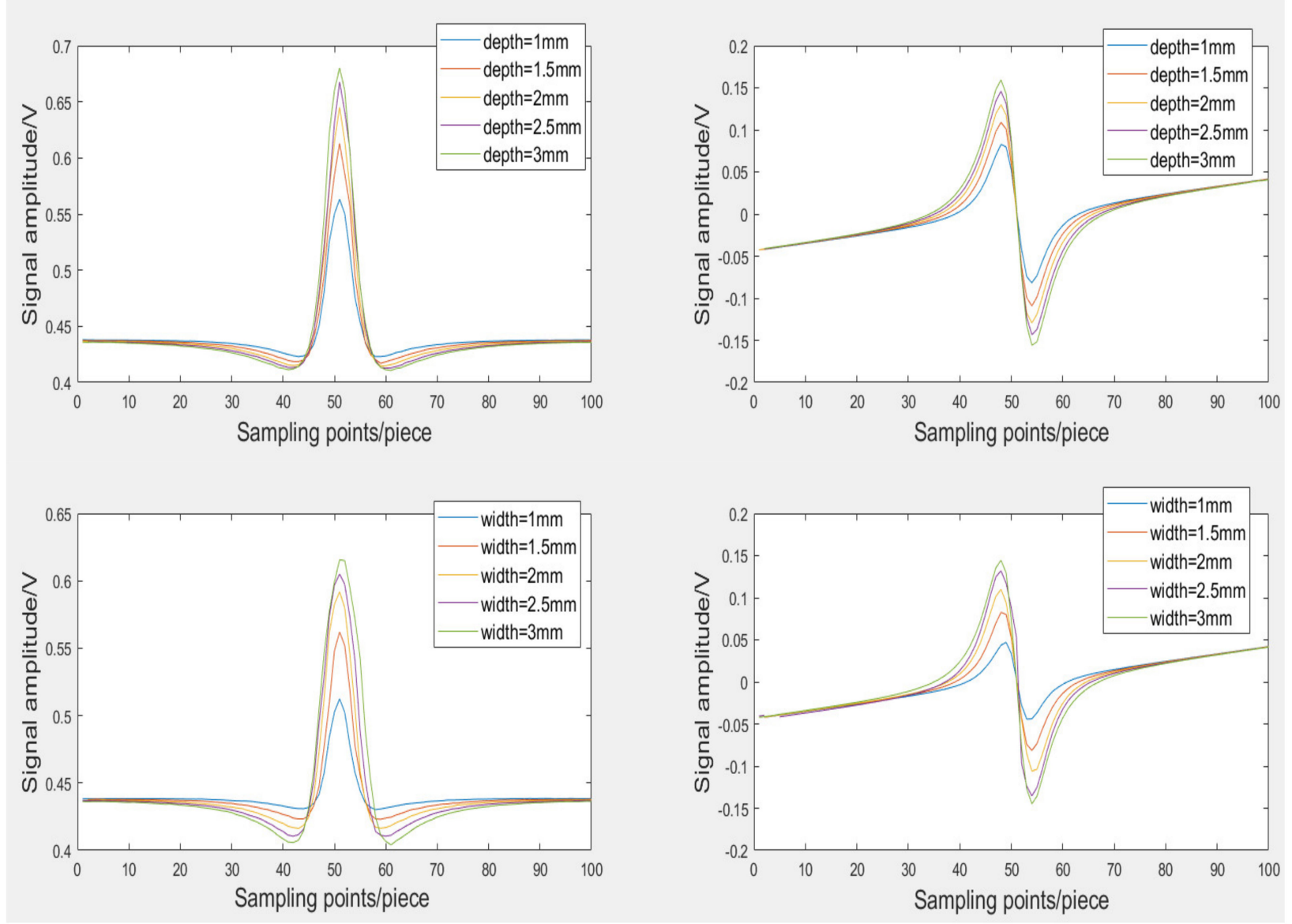

Figure 5. Magnetic field distribution of defects in $\mathrm{x}$ and $\mathrm{z}$ directions of different sizes.

In Figure 5, the LMF of a defect is within a certain range. To accurately identify and reconstruct a defect, the LMF should be measured as completely as possible. However, at a distance from the defect, the LMF is usually weak and difficult to distinguish from interference. The boundary of LMF in this paper is that the absolute value of LMF reduces to $10 \%$ of the maximum in the $\mathrm{z}$ direction. Beyond this range, the LMF is relatively small and negligible.

According to Formula (1), if $\mathrm{z}=\mathrm{z}_{0}$ unchanged, $\mathrm{H}_{\mathrm{z}}\left(\mathrm{x}, \mathrm{z}_{0}\right)$ is the maximum when $x=-\sqrt{a^{2}+z_{0}^{2}}$. The leakage magnetic field distributes in $2 L$ centered on the defect. According to Equation (4), L is calculated by Equation (6).

$$
\ln \frac{\left[(-\mathrm{L}-\mathrm{a})^{2}+\mathrm{z}_{0}^{2}\right]}{\left[(-\mathrm{L}+\mathrm{a})^{2}+\mathrm{z}_{0}^{2}\right]}=\frac{1}{10} \ln \frac{\left[\left(-\sqrt{\mathrm{a}^{2}+\mathrm{z}_{0}^{2}}-\mathrm{a}\right)^{2}+\mathrm{z}_{0}^{2}\right]}{\left[\left(-\sqrt{\mathrm{a}^{2}+\mathrm{z}_{0}^{2}}+\mathrm{a}\right)^{2}+\mathrm{z}_{0}^{2}\right]}
$$

The detection speed is $\mathrm{v} \mathrm{m} / \mathrm{s}$, and the sampling speed is s point/s. $\mathrm{J}_{0}$ is a sampling point in the $\mathrm{z}$ direction. If the distance between $\mathrm{j}_{0}$ and the center of a defect is less than $\mathrm{L}+\sqrt{\mathrm{a}^{2}+\mathrm{z}_{0}^{2}}$, there will be a maximum point in the $\mathrm{x}$ direction and a minimum point in the $z$ direction from sampling point $j_{0}-B$ to $j_{0}+B$.

$$
\mathrm{B}=\frac{\left(\mathrm{L}+\sqrt{\mathrm{a}^{2}+\mathrm{z}_{0}^{2}}\right) \mathrm{s}}{\mathrm{v}}
$$


The absolute value of the difference between the output signals of the two sensors is large at the maximum point, so it is beneficial to find the reference signal. The absolute value of the difference between the outputs of two sensors in sampling point $\mathrm{j}$ is denoted by aj. When sampling point $\mathrm{j}_{0}$ is processed, $\mathrm{aj}_{0}-\mathrm{B}$ to $\mathrm{aj}_{0}+\mathrm{B}$ are calculated first. Secondly, the maximum in $a_{0}-B$ to $a j_{0}+B$ is found. The maximum of ith pair of sensors is denoted by MAXi. At last, the pair of sensors with the smallest MAXi $(i=1,2, \ldots, N)$ is found and their output is taken as the reference signal.

\subsection{Filtering Algorithm}

As shown in Figure 2, two rows of sensors are arranged at intervals along the y direction below a yoke to detect magnetic fields in the $x$ and $z$ directions, respectively. The distance between the two rows of magnetic sensors is $\sqrt{a^{2}+z_{0}^{2}}$. The two magnetic sensors $\mathrm{Sx}[\mathrm{i}]$ and $\mathrm{Sz}[\mathrm{i}](\mathrm{i}=1,2, \ldots, \mathrm{N})$ are a pair, and there are $\mathrm{N}$ pairs of magnetic sensors. The filtering steps are as follows.

1. Each sensor output is sampled, and the number of sampling points is denoted by M. The sampling results of $S x[i]$ and $S z[i]$ are array $\operatorname{Sx}[i, j]$ and $S z[i, j](j=1,2, \ldots, M)$.

2. The array $R_{x}[i, k]$ and $R_{z}[i, k]$ is calculated:

$$
\begin{gathered}
R_{x}[i, k]=\left\{\begin{array}{c}
S_{x}[i, 1] 1 \leq k \leq B \\
S_{x}[i, j] B<k \leq M+B \\
S_{x}[i, M] M+B<k \leq M+2 B
\end{array}\right. \\
R_{z}[i, k]=\left\{\begin{array}{c}
S_{z}[i, 1] 1 \leq k \leq B \\
S_{z}[i, j] B<k \leq M+B \\
S_{z}[i, M] M+B<k \leq M+2 B
\end{array}\right.
\end{gathered}
$$

$\mathrm{q}$ is a loop variable with an initial value of $\mathrm{B}+1$.

3. $\operatorname{MAX}[\mathrm{i}, \mathrm{q}]=\operatorname{MAX}\left|\mathrm{R}_{\mathrm{x}}[\mathrm{i}, \mathrm{p}]-\mathrm{R}_{\mathrm{z}}[\mathrm{i}, \mathrm{p}]\right|(\mathrm{p}=\mathrm{q}-\mathrm{B}, \mathrm{q}-\mathrm{B}+1, \ldots, \mathrm{q}+\mathrm{B})$.

4. The minimum in $\operatorname{MAX}[\ldots, \mathrm{q}](\mathrm{i}=1,2, \ldots, \mathrm{N})$ is found. The number of the pair that has the minimum is denoted by $\mathrm{i} 0$. The sampling point of the pair sensors are taken as the reference signal. $R_{x}[i, q]-R_{x}\left[i_{0}, q\right], R_{z}[i, q]-R_{z}\left[i_{0}, q\right](i=1,2, \ldots, N)$ : The differences are taken as the filtering results of each sensor at this sampling point.

5. $q=q+1$. If $q \leq M+B$, the process returns to step 3 , otherwise the filtering ends.

\section{Experimental Results and Analysis}

\subsection{Finite Element Simulation Results and Analysis}

The finite element analysis software used in this paper is Ansys Maxwell. An MFL detection model is built as shown in Figure 6. The yoke is made of ferromagnetic material. The excitation coil adopts 4000 turns of copper wire. The DC excitation voltage is $60 \mathrm{~V}$, and the lift-off between the rail and the yoke is $2.0 \mathrm{~mm}$. Two detection points with a lift-off of $2.0 \mathrm{~mm}$ are set up above the rail.

The width and depth of the defect are $2.0 \mathrm{~mm}$ and $1.0 \mathrm{~mm}$, respectively and the lift-off is $2.0 \mathrm{~mm}$, which means that $\mathrm{a}=1.0 \mathrm{~mm}, \mathrm{~b}=1.0 \mathrm{~mm}$, and $\mathrm{z}=2.0 \mathrm{~mm}$. According to Formula (4), when the distance between a pair of sensors is $\sqrt{\mathrm{a}^{2}+\mathrm{z}^{2}}$, which is $2.2 \mathrm{~mm}$, the absolute value of the difference between the outputs of the two sensors is the maximum. The distance between two sensors is set to $1.8 \mathrm{~mm}, 2.2 \mathrm{~mm}$, and $2.6 \mathrm{~mm}$, respectively. The simulation results are shown in Figure $7 \mathrm{a}-\mathrm{c}$. 


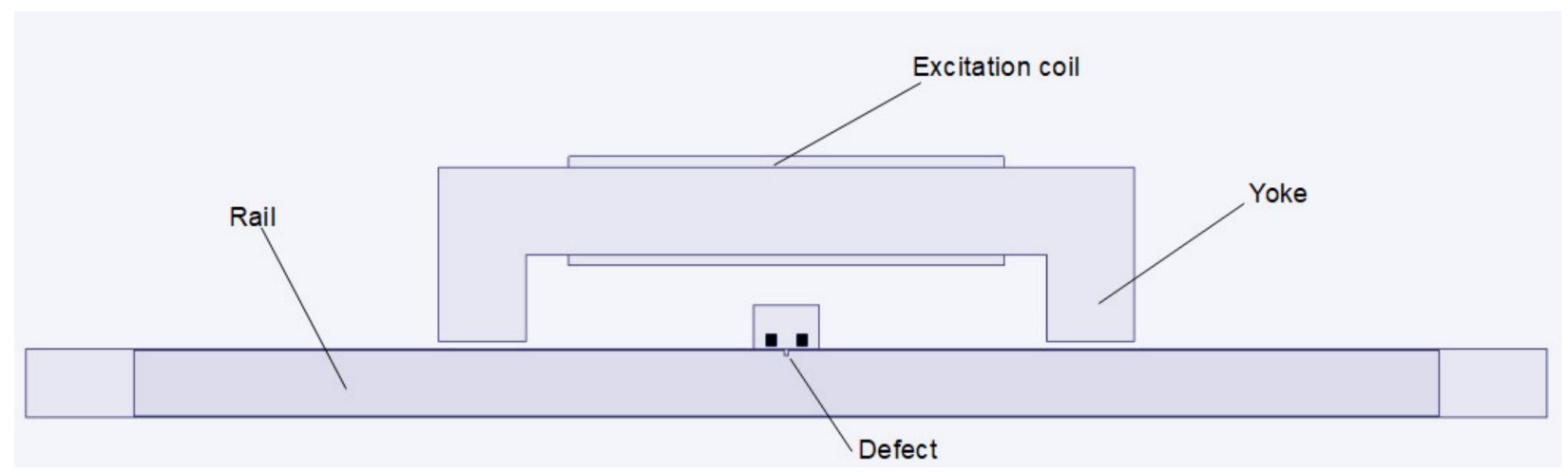

Figure 6. Simulation model.

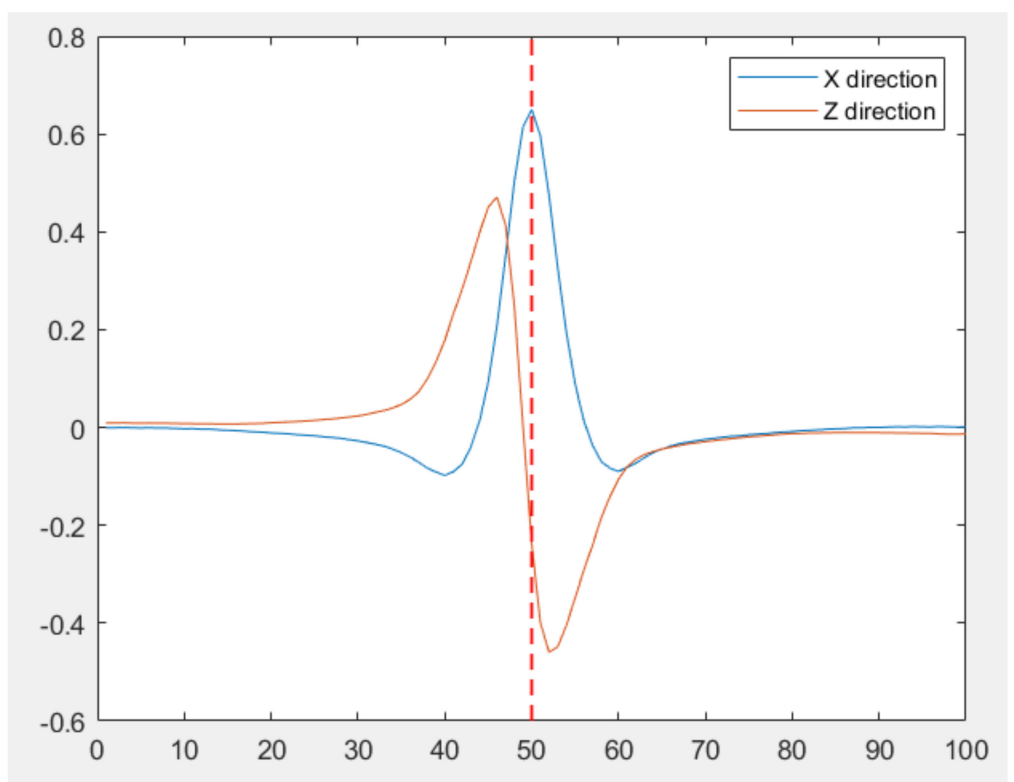

(a)

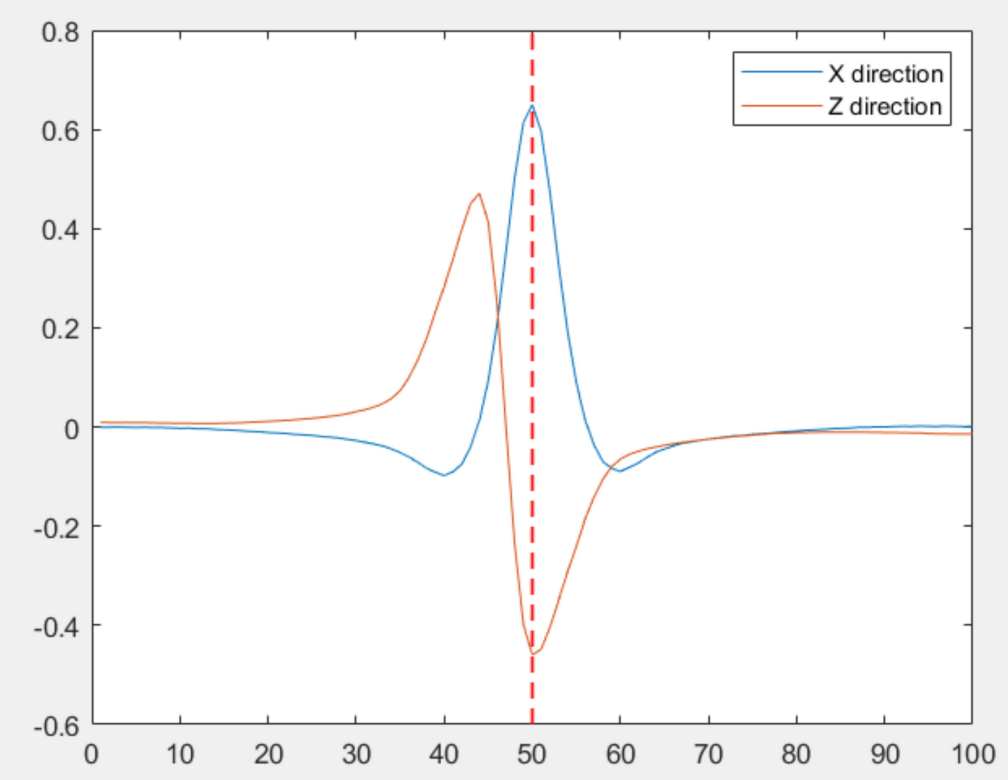

(b)

Figure 7. Cont. 


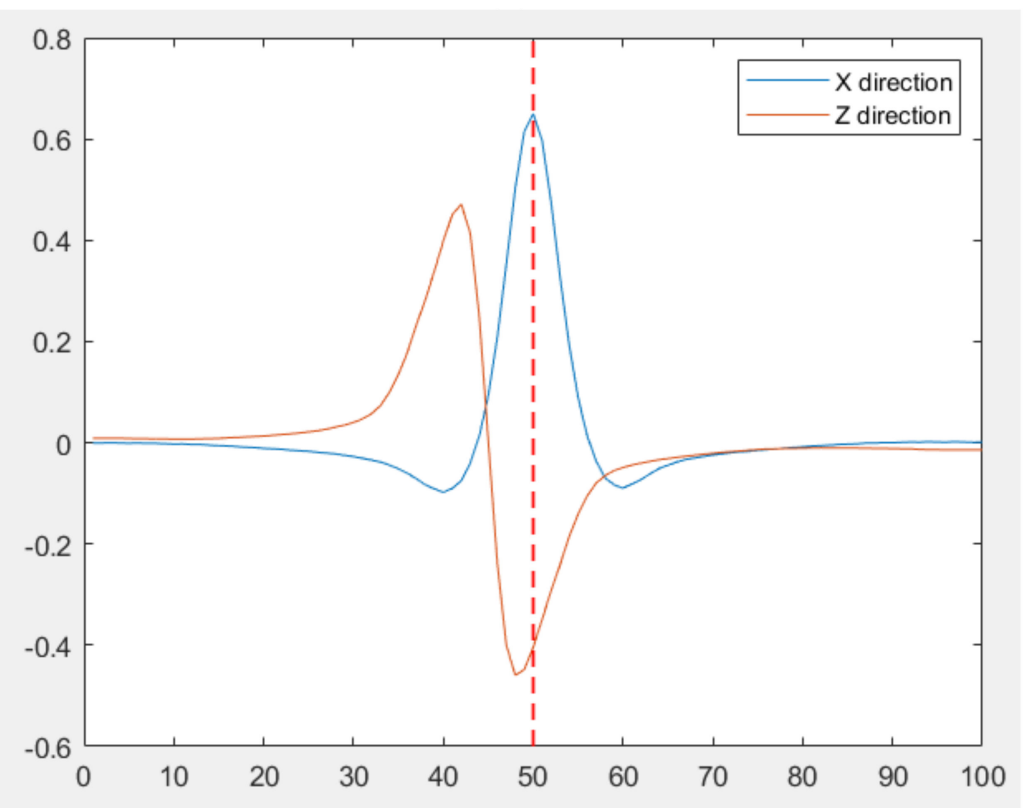

(c)

Figure 7. The $x$ and $z$ direction simulation results with different distance. (a) $1.8 \mathrm{~mm}$; (b) $2.2 \mathrm{~mm}$; (c) $2.6 \mathrm{~mm}$.

According to the simulation results in Figure $7 \mathrm{a}-\mathrm{c}$, the phase difference of the pair of sensors becomes increasingly significant with the increase in the distance between them. When the distance is $2.2 \mathrm{~mm}$, one sensor detects the maximum in the $\mathrm{x}$ direction and the other sensor detects the minimum in the $\mathrm{z}$ direction, which is indicated by the red line in Figure 7 . The absolute value of the difference between them is the maximum which is in accordance with the above conclusion.

\subsection{Physical Experiment Results and Analysis}

\subsubsection{Experiment System}

An experimental system was built and is shown in Figure 8. The system consists of a computer, a signal conditioning circuit, a DAQ card, and a probe. The sensor is an SL-106C, whose length and width are both $1.5 \mathrm{~mm}$. The amplifier is AD620, and the magnification is 100. The DAQ card is ADLINK DAQ2208, and the sampling frequency of each channel is set to $4 \mathrm{kHz}$. The probe, which consists of two rows, eight sensors per row, and an excitation device, is mounted on a detection car that is placed on the rail. The detection speed was $2.0 \mathrm{~m} / \mathrm{s}$.

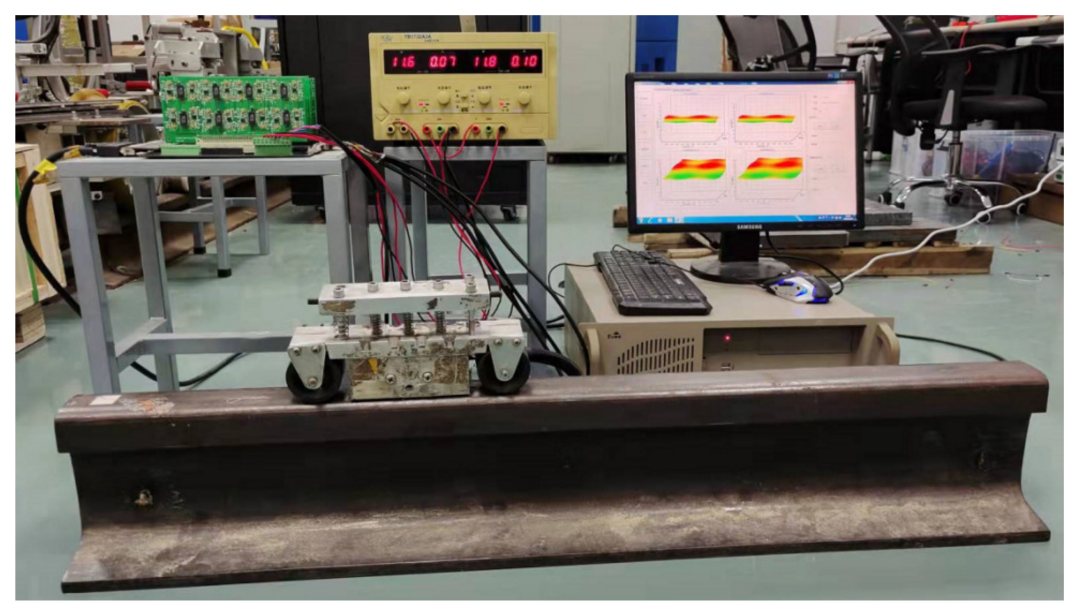

Figure 8. MFL detection system. 


\subsubsection{Single Defect Experiment}

The detection object is an artificial defect in the surface of a used rail, as shown in Figure 9. The direction of detection is from left to right. A wire is tied to the rail, which will change the lift-off of the handcart to simulate the vibration. If no vibration is encountered, the lift-off of the sensor is $2.0 \mathrm{~mm}$, and when the handcart wheel rolls over the wire, the lift-off will fluctuate within $2.0 \sim 3.5 \mathrm{~mm}$. The defect is $2.0 \mathrm{~mm}$ in width and $1.0 \mathrm{~mm}$ in depth. Therefore, $\mathrm{a}=1.0 \mathrm{~mm}, \mathrm{z}_{0}=2.0 \mathrm{~mm}$. The distance between a pair of sensors is $\sqrt{\mathrm{a}^{2}+\mathrm{z}_{0}^{2}}$, that is $2.2 \mathrm{~mm}$. L is $41.4 \mathrm{~mm}$ and B is 87 , according to Formulas (5) and (6), respectively.

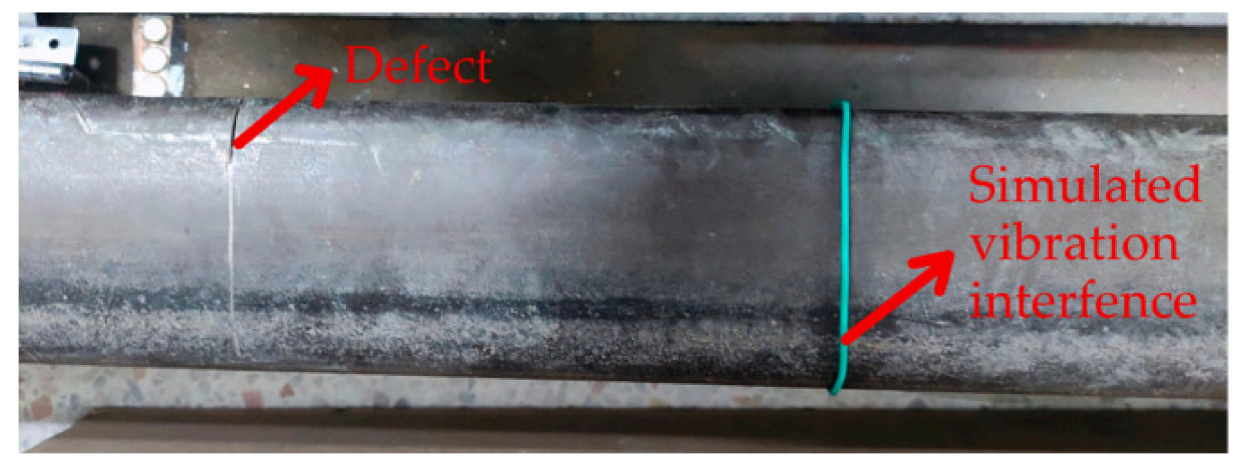

Figure 9. A rail with artificial defect.

A pair of sensors which detect the defect in $\mathrm{x}$ and $\mathrm{z}$ directions, respectively, are arranged in the probe. The distance between them is set to $1.8 \mathrm{~mm}, 2.2 \mathrm{~mm}$, and $2.6 \mathrm{~mm}$ respectively. The detection results are shown in Figure 10.

According to Figure $10 \mathrm{a}-\mathrm{c}$, the phase of the signal of two sensors is different near the defect and when the sensors pass through the defect, the difference in the phase increases with increases in the sensor distance, which is shown in the red region. As shown in the blue region, if vibration has occurred, the phases of the two signals are basically similar. Therefore, the phase relationship of the two signals can be used to determine whether there is a defect. In addition, when the distance between a pair of sensors is $\sqrt{\mathrm{a}^{2}+\mathrm{z}_{0}^{2}}$, which is $2.2 \mathrm{~mm}$, a sensor detects the maximum in the $x$ direction and the other detects the minimum in the $\mathrm{z}$ direction, and the absolute value of the difference between the outputs of the two sensors is the maximum.

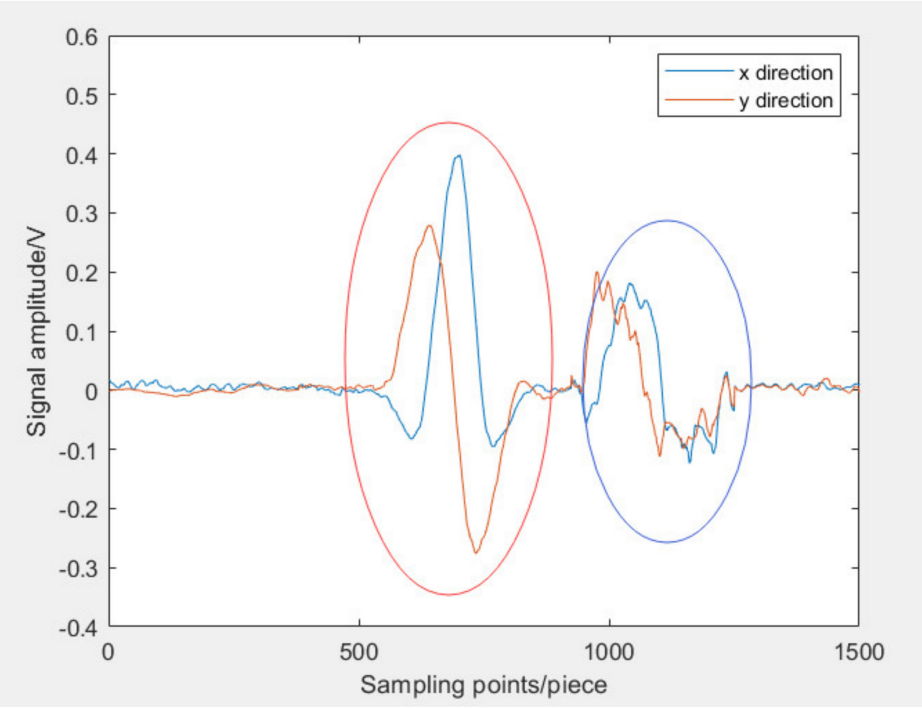

(a)

Figure 10. Cont. 


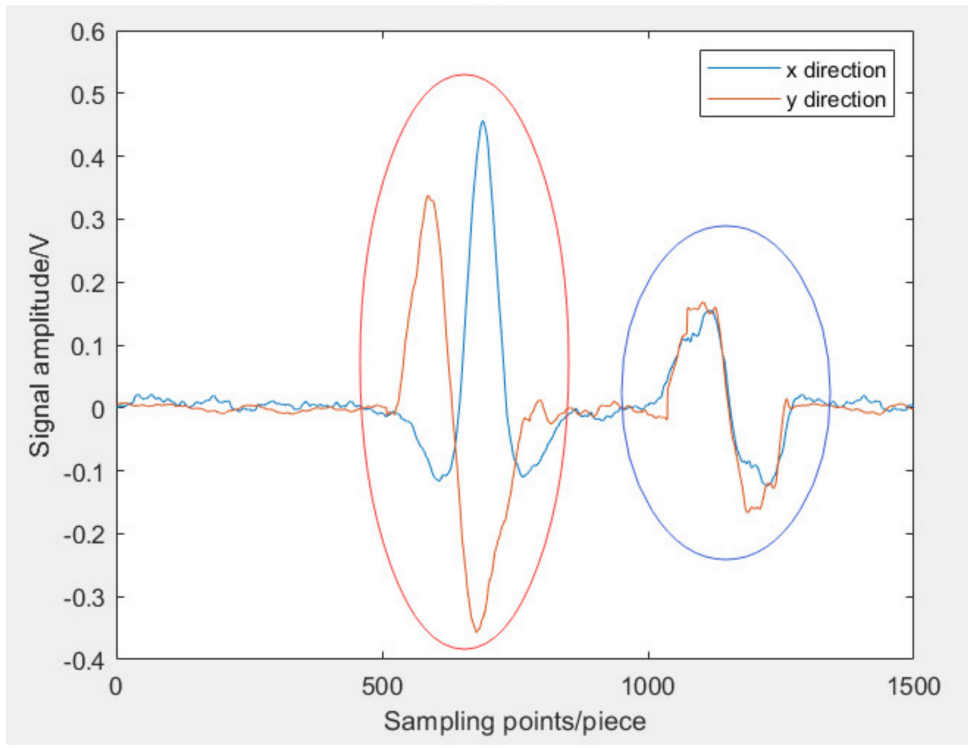

(b)

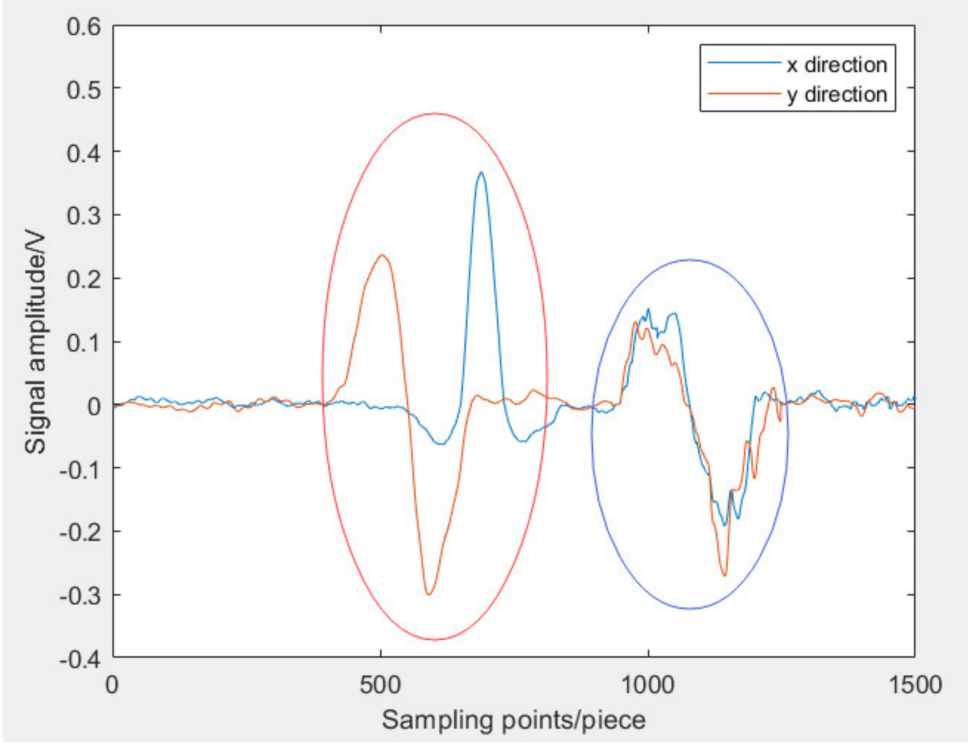

(c)

Figure 10. Detection results with different distances. (a) $1.8 \mathrm{~mm}$; (b) $2.2 \mathrm{~mm}$; (c) $2.6 \mathrm{~mm}$.

\subsubsection{Multiple Defects Experiment}

The detection results in the $\mathrm{x}$ and $\mathrm{z}$ directions of four different defects are shown in Figure $11 \mathrm{a}-\mathrm{d}$, respectively. The lift-off is $2.0 \mathrm{~mm}$. The distance between two sensors is $2.2 \mathrm{~mm}$.

As shown in Figure 11a-d, the amplitude of the signal will increase when the depth of the defect increases. When the distance between a pair of sensors is $2.2 \mathrm{~mm}$ in Figure 11a,b, one sensor detects the maximum in the $x$ direction and the other detects the minimum in the $\mathrm{z}$ direction, and the absolute value of the difference between the outputs of the two sensors is the maximum. As shown in Figure 11c,d, the width becomes larger when a sensor is directly above the larger defect and its output is the maximum in the $x$ direction; the other does not measure the minimum in the $\mathrm{z}$ direction, but the absolute value of the difference between them is greater than that of a small defect. Therefore, the distance calculated according to the minimum defect is also applicable to the detection of large defects. 


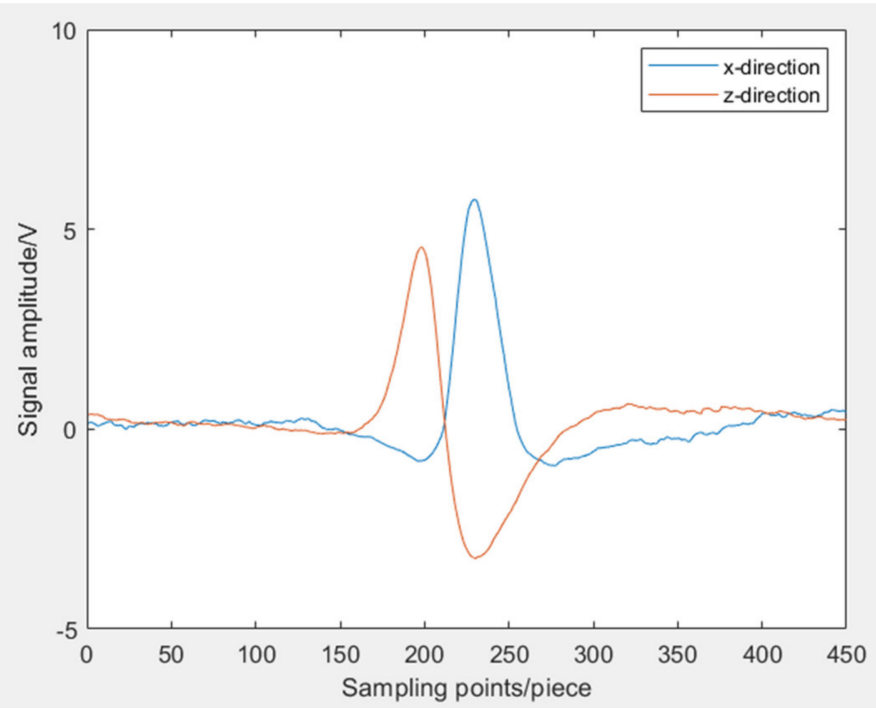

(a)

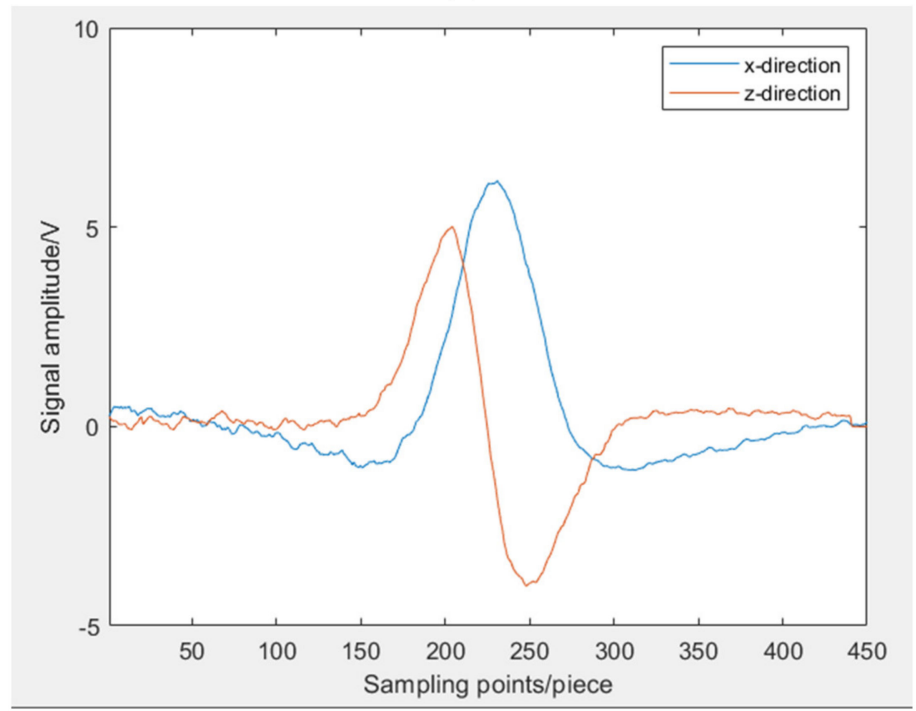

(c)

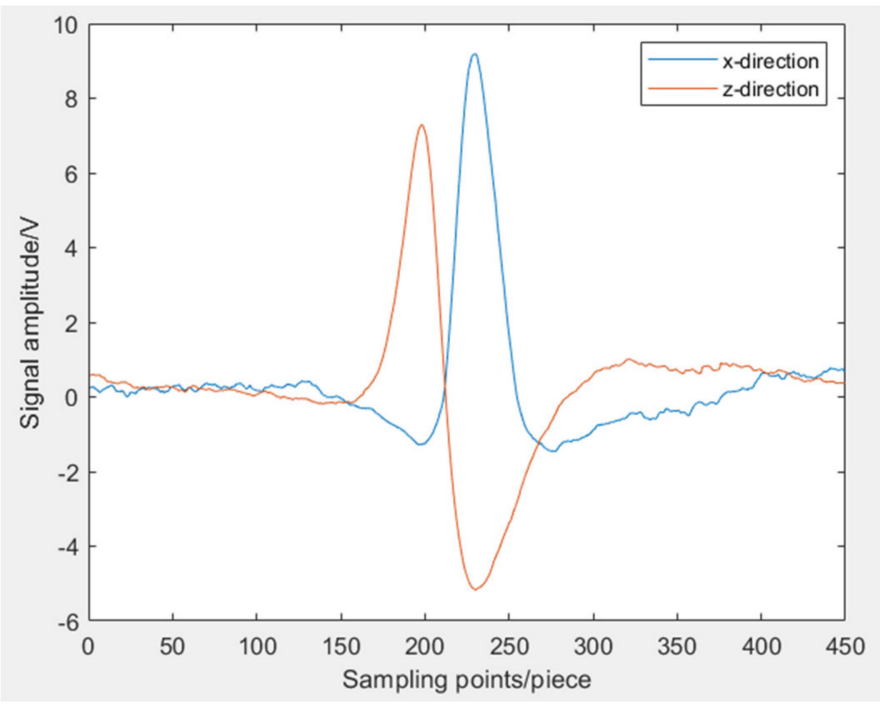

(b)

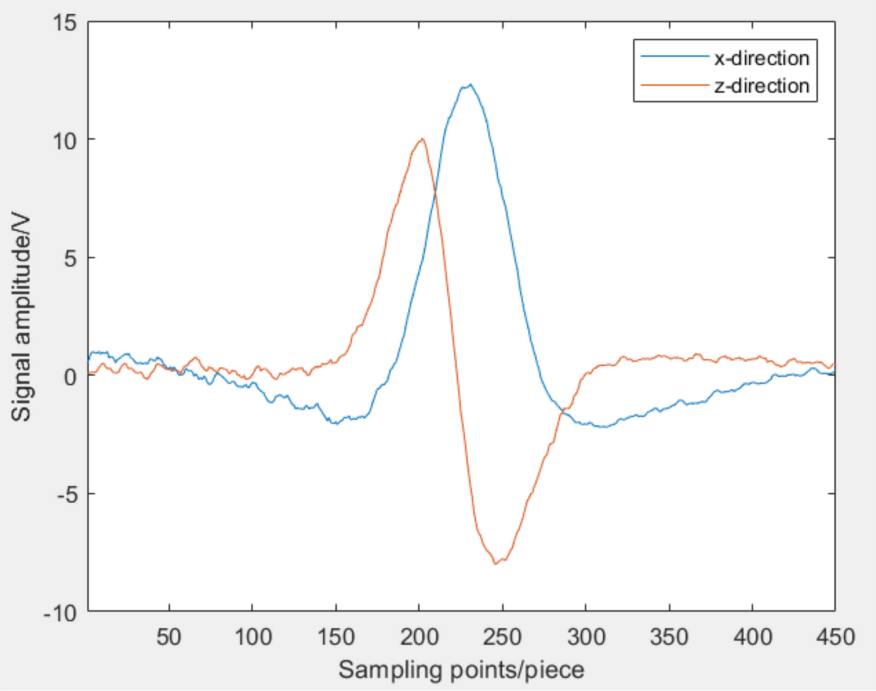

(d)

Figure 11. Detection results with different defects. (a) width $=2 \mathrm{~mm}$, depth $=1 \mathrm{~mm}$; (b) width $=2 \mathrm{~mm}$, depth $=2 \mathrm{~mm}$; (c) width $=3 \mathrm{~mm}$, depth $=1 \mathrm{~mm}$; (d) width $=3 \mathrm{~mm}$, depth $=2 \mathrm{~mm}$.

A used rail with eight artificial defects is detected, and a wire is tied to the rail also, as shown in Figure 12. The width and depth of each defect are shown in Table 1. The lift-off of the sensor is also fixed at $2.0 \mathrm{~mm}$. The distance between the two sensors is $2.2 \mathrm{~mm}$.

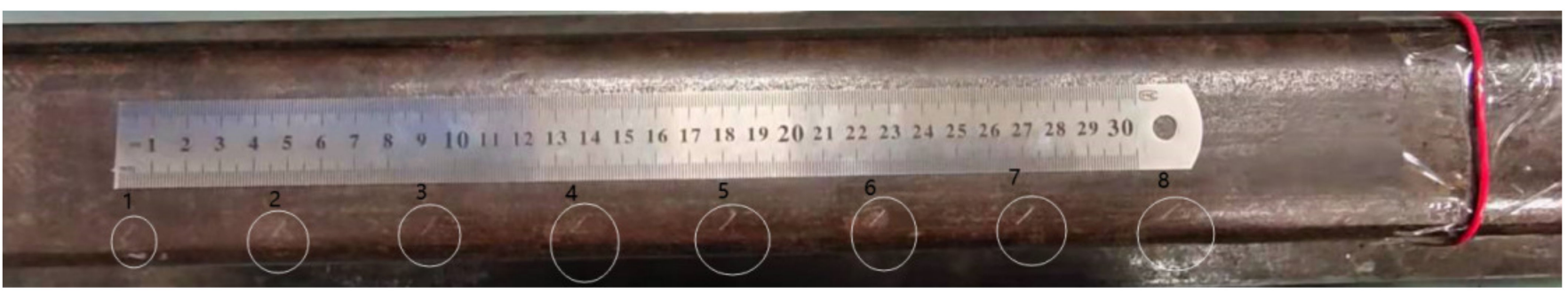

Figure 12. A rail with multiple artificial defects. 
Table 1. The width and depth of each defect.

\begin{tabular}{lcccccccc}
\hline & Defect 1 & Defect 2 & Defect 3 & Defect 4 & Defect 5 & Defect 6 & Defect 7 & Defect 8 \\
\hline Width & $2.0 \mathrm{~mm}$ & $2.2 \mathrm{~mm}$ & $2.2 \mathrm{~mm}$ & $2.5 \mathrm{~mm}$ & $2.5 \mathrm{~mm}$ & $2.5 \mathrm{~mm}$ & $2.5 \mathrm{~mm}$ & $2.5 \mathrm{~mm}$ \\
Depth & $1.0 \mathrm{~mm}$ & $1.2 \mathrm{~mm}$ & $1.2 \mathrm{~mm}$ & $2.0 \mathrm{~mm}$ & $2.5 \mathrm{~mm}$ & $2.5 \mathrm{~mm}$ & $2.8 \mathrm{~mm}$ & $3.0 \mathrm{~mm}$ \\
\hline
\end{tabular}

Figure 13 shows a multichannel three-dimensional diagram of the sensors. The sensors near the outer edge all detected defect signals, and all the sensors were affected by lift-off interference and the vibration signals changed synchronously. Figure 14 shows the original signal of the seventh sensor in blue and the reference signal in red. The vibration signals are marked with rectangular boxes and the defect signals are marked with elliptical boxes. Obviously, the amplitude of the signal caused by vibration is similar to that caused by a small defect, so the detection is disturbed by vibration. The reference signal retains the changes caused by vibration and contains no defect signal.

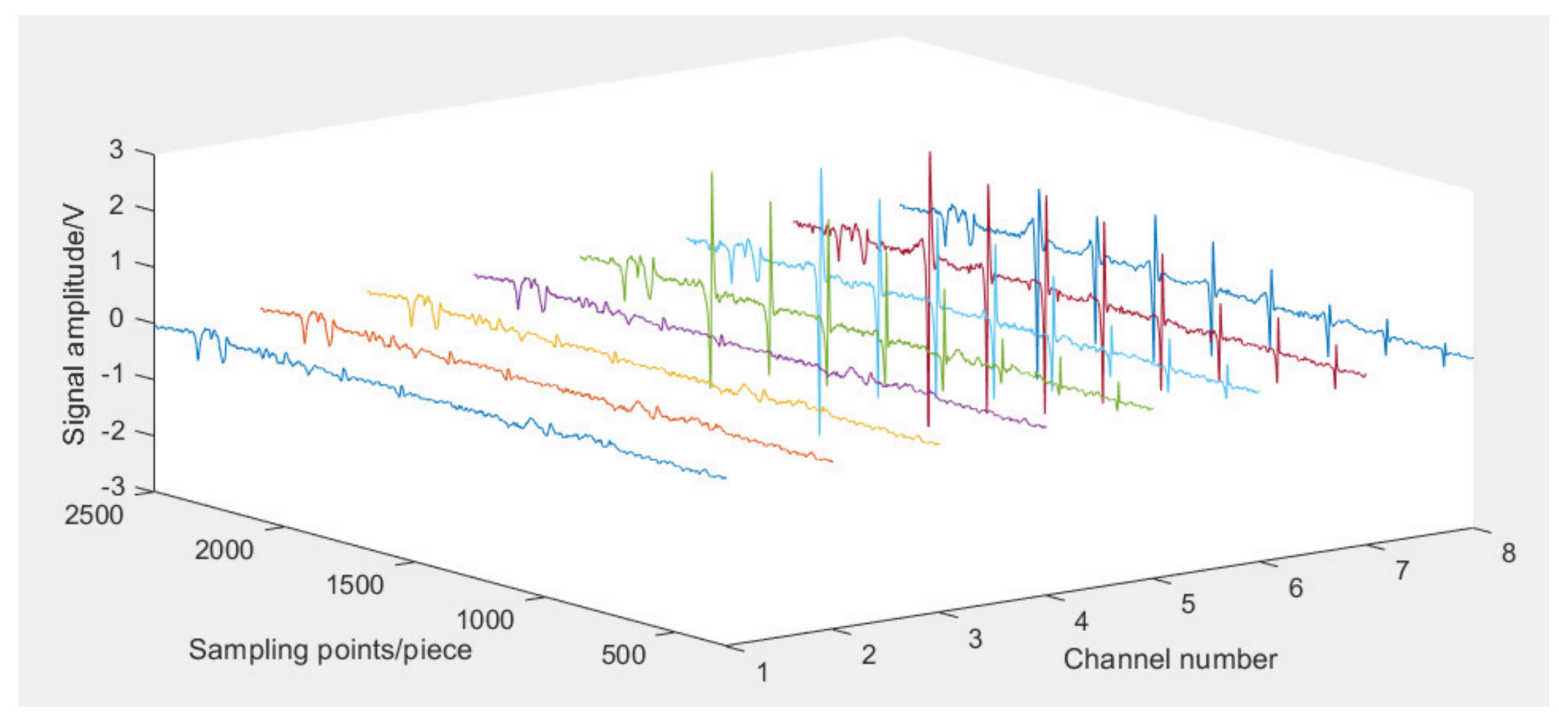

Figure 13. Multichannel original MFL signal.

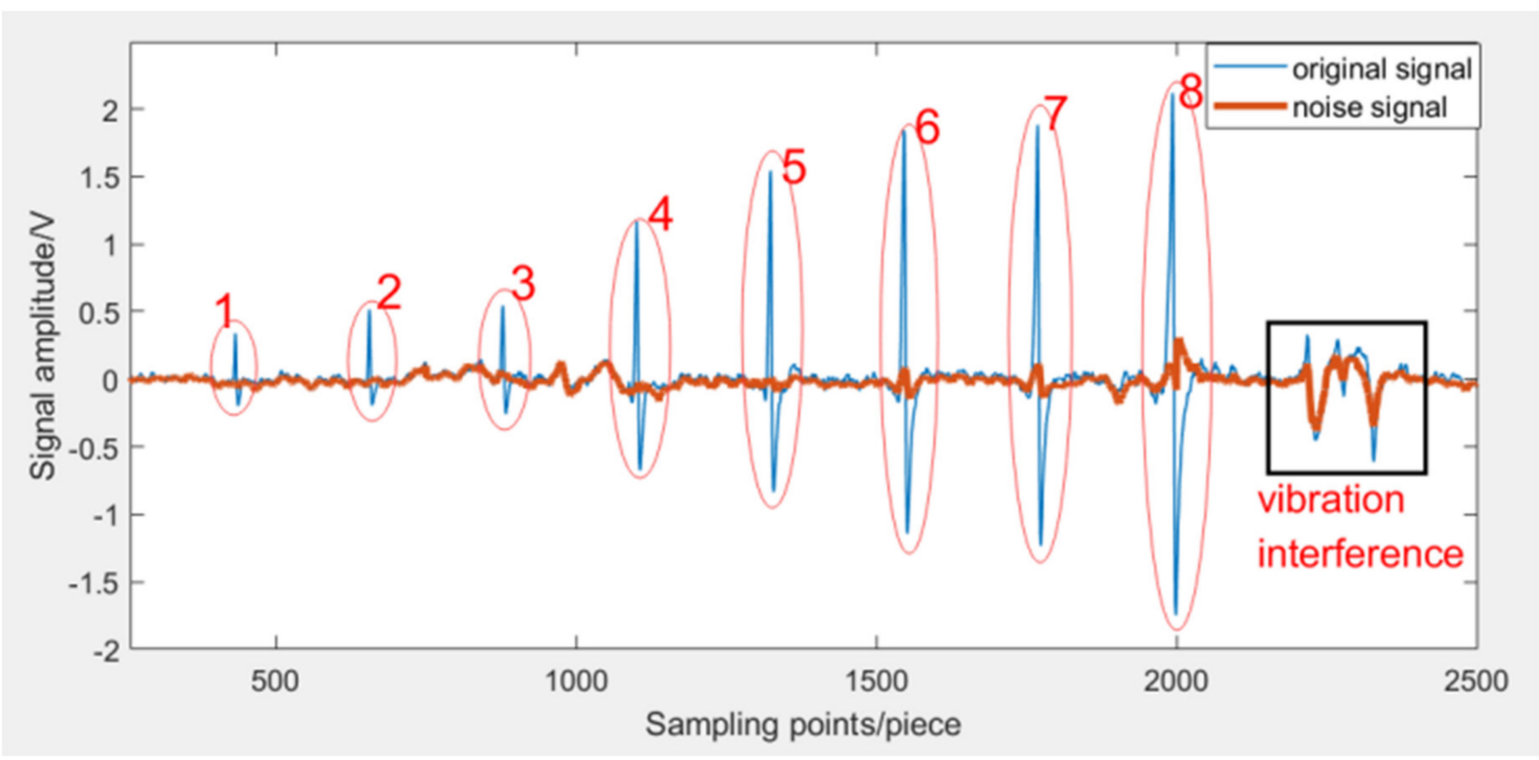

Figure 14. Original signal and vibration signal of the seventh sensor. 
The filtered signal is shown in Figure 15. Compared with the original signal in Figure 14, the defect signal is basically unchanged, while the vibration signal decreases significantly. Figure 16 shows the three-dimensional image of the multichannel filtered signal. After filtering, the vibration interference is obviously reduced.

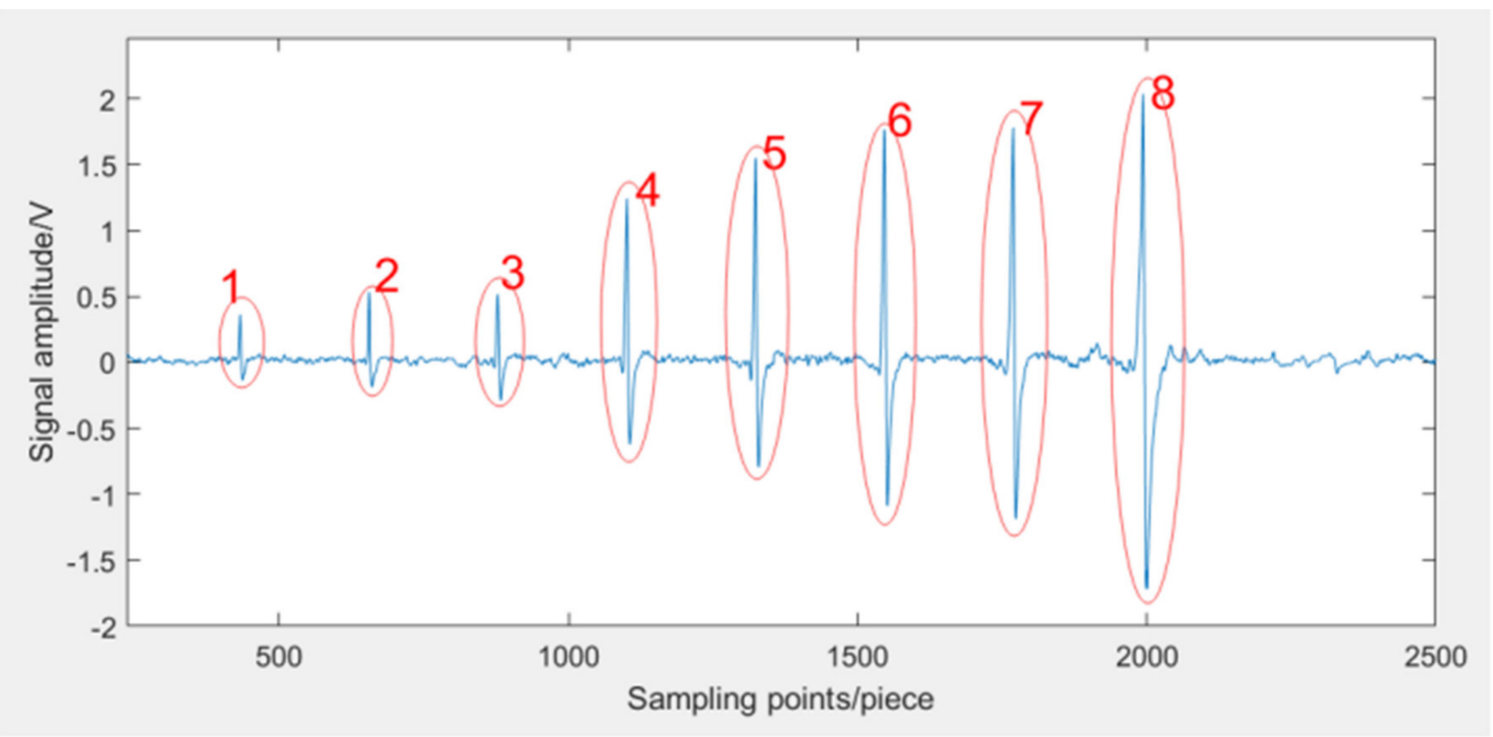

Figure 15. Filtered signal of the seventh sensor.

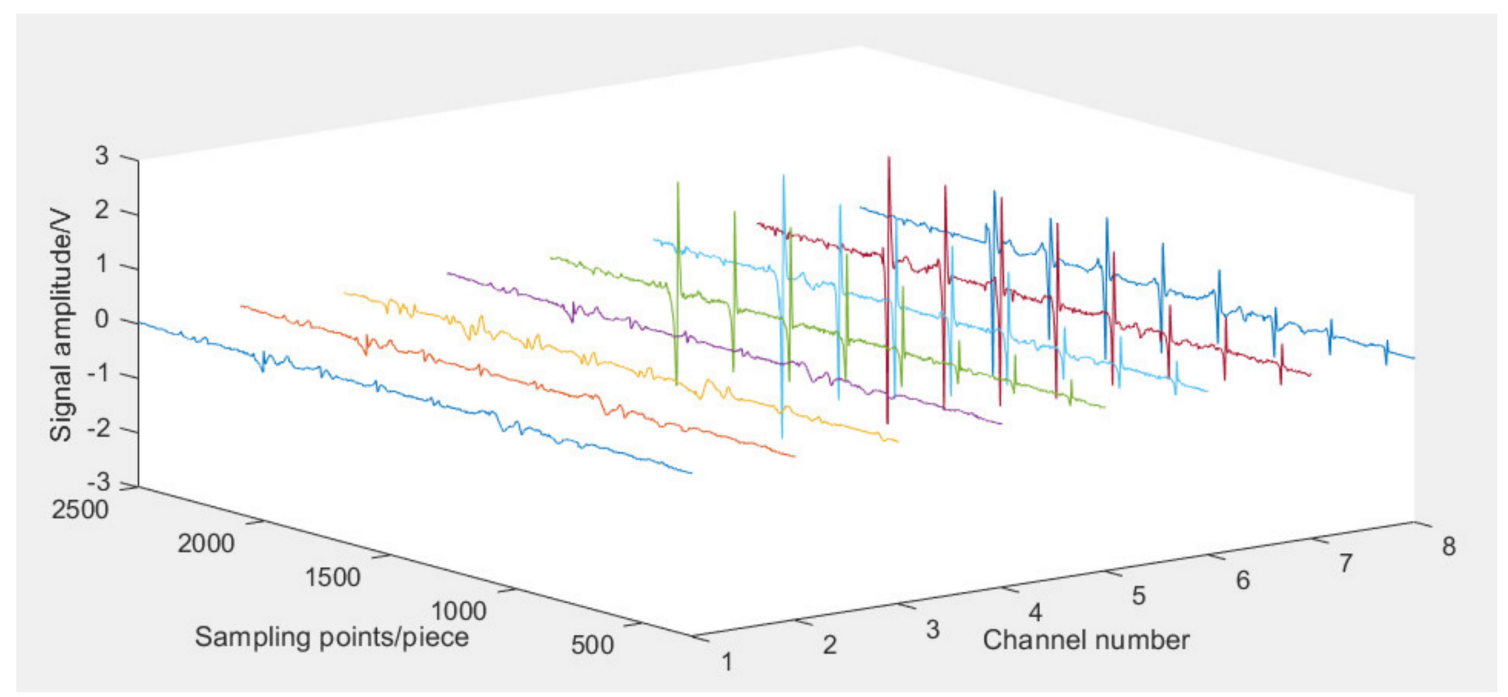

Figure 16. Multichannel filtered signal.

\section{Conclusions}

In this paper, a filtering method is proposed to suppress the lift-off interference of rail defect MFL detection. According to the different signal characteristics of sensors in $\mathrm{x}$ and $\mathrm{z}$ directions, the structure of the array sensor is adopted, which can effectively extract the reference signal that contains only interference signals such as lift-off. Thus, the lift-off interference can be suppressed, and a relatively complete waveform of defect leakage magnetic field detection will be obtained. In the future, the natural defects detection test will be carried out, and the identification and reconstruction methods of defects will be studied.

Author Contributions: Conceptualization, Y.J. and Y.L.; methodology, Y.J.; software, Y.L.; validation, Y.J., Y.L. and L.X.; formal analysis, Y.J.; investigation, Y.Z.; resources, Y.L.; data curation, Y.L.; writing- 
original draft preparation, Y.L.; writing—review and editing, Y.J.; visualization, H.Z.; supervision, P.W.; project administration, P.W.; funding acquisition, P.W. All authors have read and agreed to the published version of the manuscript.

Funding: This work was funded by the National Key R\&D Program of China (2018YFB2100903) and Scientific Research Projects of China Academy of Railway Sciences (2020YJ153).

Institutional Review Board Statement: Not applicable.

Informed Consent Statement: Not applicable.

Conflicts of Interest: The authors declare no conflict of interest.

\section{References}

1. Zhang, H.; Song, Y.N.; Wang, Y.N. Review of rail defect non-destructive testing and evaluation. Chin. J. Sci. Instrum. 2019, 40, $11-25$.

2. Alahakoon, S.; Sun, Y.Q.; Spiryagin, M.; Cole, C. Rail Flaw Detection Technologies for Safer, Reliable Transportation: A Review. J. Dyn. Syst. Meas. Control 2018, 140, 020801. [CrossRef]

3. Fu, L.Z.; Wu, J.J.; Lang, X.W. Experiment research on switch rail defect monitoring using ultrasonic guided waves. Railway Engineering 2018, 31, 129-133.

4. Miki, M.; Ogata, M. Phased array ultrasonic testing methods for welds in bogie frames of railway vehicles. Insight 2015, 57, 382-388. [CrossRef]

5. $\mathrm{Hu}, \mathrm{Q} . \mathrm{W} . ;$ Wang, X.B.; Wu, W. Eddy current testing and evaluation method for fine cracks on rail surface. Equip. Manag. Maint. 2021, 42, 34-35.

6. Wilson, J.W.; Tian, G.Y. 3D magnetic field sensing for magnetic flux leakage defect characterisation. Insight 2006, 48, 357-359. [CrossRef]

7. Gao, L. Research on Image Detection and Recognition Method of Steel Plate Surface Defect Based on Magnetic Flux Leakage Signal. Master's Thesis, Northeastern University, Shen Yang, China, 2017.

8. Azari, H.; Al Ghorbanpoor; Shams, S. Development of Robotic Nondestructive Testing of Steel Corrosion of Prestressed Concrete Bridge Girders using Magnetic Flux Leakage System. Transp. Res. Record. 2020, 2674, 466-476. [CrossRef]

9. Peng, X.; Anyaoha, U.; Tsukada, K. Analysis of Magnetic-Flux Leakage(MFL) Data for Pipeline Corrosion Assessment. IEEE Trans. Magn. 2020, 57, 6200410. [CrossRef]

10. Piao, G.Y.; Guo, J.B.; Hu, T.H.; Leung, H.; Deng, Y.M. Fast reconstruction of 3-D defect profile from MFL signals using key physics-based parameters and SVM. NDT E Int. 2019, 103, 26-38. [CrossRef]

11. Wu, D.H.; Su, L.X.; Wang, X.H. A Novel Non-destructive Testing Method by Measuring the Change Rate of Magnetic Flux Leakage. J. Nondestruct. Eval. 2017, 36, 24.

12. Usarek, Z.; Chmielewski, M.; Piotrowski, L. Reduction of the Velocity Impact on the Magnetic Flux Leakage Signal. J. Nondestruct. Eval. 2019, 38, 28. [CrossRef]

13. Feng, B.; Kang, Y.H.; Sun, Y.H. Magnetization Time Lag Caused by Eddy Currents and Its Influence on High-Speed Magnetic Flux Leakage Testing. Res. Nondestruct. Eval. 2019, 30, 189-204. [CrossRef]

14. Karuppasamy, P.; Abudhahir, A.; Jayakumar, T. Model-Based Optimization of MFL Testing of Ferromagnetic Steam Generator Tubes. J. Nondestruct. Eval. 2016, 35, 5. [CrossRef]

15. Watson, J.M.; Liang, C.W.; Sexton, J.; Missous, M. Magnetic field frequency optimisation for MFL imaging using QWHE sensors. Insight 2020, 62, 396-401. [CrossRef]

16. Zhang, O.; Wei, X.Y. De-noising of Magnetic Flux Leakage Signals Based on Wavelet Filtering Method. Res. Nondestruct. Eval. 2019, 30, 269-286. [CrossRef]

17. Liu, S.W.; Sun, Y.H.; Deng, Z.Y.; He, L.S. A novel method of omnidirectional defects detection by MFL testing under single axial magnetization at the production stage of lathy ferromagnetic materials. Sens. Actuator A-Phys. 2017, 262, 35-45. [CrossRef]

18. Liu, X.C.; Wang, Y.J.; Wu, B.; He, C.F. Design of Tunnel Magnetoresistive-Based Circular MFL Sensor Array for the Detection of Flaws in Steel Wire Rope. J. Sens. 2016, 6, 198065.

19. Wu, D.H.; Liu, Z.T.; Su, L.X. New MFL detection method based on differential peak extraction using dual sensors. Chin. J. Sci. Instrum. 2016, 37, 1218-1225.

20. Ding, S.Y. Research on De-Noising and Recognition of Rail Magnetic Flux Leakage Signal Based on Adaptive Filtering and Random Forest. Master's Thesis, Nanjing University of Aeronautics and Astronautics, Nan Jing, China, 2020.

21. Ji, K.L.; Wang, P.; Jia, Y.L.; Ye, Y.F.; Ding, S.Y. Adaptive Filtering Method of MFL Signal on Rail Top Surface Defect Detection. IEEE Access 2021, 9, 87351-87359. [CrossRef]

22. Jia, Y.L.; Zhang, S.C.; Wang, P.; Ji, K.L. A Method for Detecting Surface Defects in Railhead by Magnetic Flux Leakage. Appl. Sci. 2021, 11, 9489. [CrossRef] 